\title{
A multilocus phylogeny of the Streptomyces griseus 16S rRNA gene clade: use of multilocus sequence analysis for streptomycete systematics
}

Correspondence

Ying Huang

huangy@im.ac.cn

\section{Yinping Guo, ${ }^{1,2}$ Wen Zheng, ${ }^{1}$ Xiaoying Rong ${ }^{1,2}$ and Ying Huang ${ }^{1}$}

\author{
${ }^{1}$ State Key Laboratory of Microbial Resources, Institute of Microbiology, Chinese Academy of \\ Sciences, Beijing 100101, PR China \\ ${ }^{2}$ Department of Biology, Graduate University of Chinese Academy of Sciences, Beijing 100049, \\ PR China
}

\begin{abstract}
Streptomycetes are a complex group of actinomycetes that produce diverse bioactive metabolites of commercial significance. Systematics can provide a useful framework for identifying species that may produce novel metabolites. However, previously proposed approaches to the systematics of Streptomyces have suffered from either poor interlaboratory comparability or insufficient resolution. In particular, the Streptomyces griseus 16S rRNA gene clade is the most challenging and least defined group within the genus Streptomyces in terms of phylogeny. Here we report the results of a multilocus sequence analysis scheme developed to address the phylogeny of this clade. Sequence fragments of six housekeeping genes, atp $D, \operatorname{gyr} B, \operatorname{rec} A, r p o B$, $\operatorname{trp} B$ and $16 \mathrm{~S}$ rRNA, were obtained for 53 reference strains that represent 45 valid species and subspecies. Analysis of each individual locus confirmed the suitability of loci and the congruence of single-gene trees for concatenation. Concatenated trees of three, four, five and all six genes were constructed, and the stability of the topology and discriminatory power of each tree were analysed. It can be concluded from the results that phylogenetic analysis based on multilocus sequences is more accurate and robust for species delineation within Streptomyces. A multilocus phylogeny of six genes proved to be optimal for elucidating the interspecies relationships within the S. griseus $16 S$ rRNA gene clade. Our multilocus sequence analysis scheme provides a valuable tool that can be applied to other Streptomyces clades for refining the systematic framework of this genus.
\end{abstract}

\section{INTRODUCTION}

The genus Streptomyces encompasses a large group of micro-organisms that are ubiquitous in nature, and wellknown producers of diverse bioactive compounds such as antibiotics. Actinomycetes make more than half of the known antibiotics derived from microbial sources, and amongst them some $75 \%$ are made by streptomycetes (Berdy, 2005). Many members of this genus also play important roles in biodegradation and bioremediation (Ishiyama et al., 2004), such as degrading lignin and recalcitrant aromatic compounds (Phelan et al., 1979; Grund et al., 1990). Notwithstanding these findings, it has

Abbreviations: K2P, Kimura two-parameter; ML, maximum-likelihood; $\mathrm{MP}$, maximum-parsimony; $\mathrm{NJ}$, neighbour-joining.

The GenBank/EMBL/DDBJ accession numbers for the sequence data reported in this paper are listed in Table 1.

A series of supplementary figures showing the chromosomal locations of the genes used, and phylogenetic trees for each protein-coding locus and for concatenated multiple genes are available with the online version of this paper. been predicted that less than $10 \%$ of streptomycete bioactive metabolites have been discovered (Watve et al., 2001; Clardy et al., 2006).

As a rich source of novel bioactive, commercially significant compounds, the genus Streptomyces has been subjected to intensive isolation and screening, resulting in more than 3000 species being described in the literature (including patents) from the 1970s. The large number of isolates and poor species definition caused overspeciation and taxonomic chaos within this genus, the largest genus in the prokaryotes. The International Streptomyces Project was launched to establish standard phenotypic criteria for Streptomyces species determination during 1964-1972. Several numerical taxonomic and chemotaxonomic studies followed, albeit with limited success (Anderson \& Wellington, 2001). Since the 1980s, the advent of molecular techniques has provided a number of genotypic approaches to investigate the taxonomy of Streptomyces, including rRNA sequence comparison, DNA-DNA hybridization and DNA fingerprinting (Watve et al., 2001; Lanoot et al., 2004, 2005a; Song et al., 2004). However, due to the respective 
drawbacks of each method, i.e. insufficient resolution, labour-intensive and high error rate, and low interlaboratory reproducibility, all have their limitations in routine use.

Despite the current availability of almost all 16S rRNA gene sequences of Streptomyces type strains in public databases contributed by researchers from several countries, many species relationships within Streptomyces remain unclear. The Streptomyces griseus 16S rRNA gene clade has become one of the most taxonomically complex groups, and one which has proved most prolific in the production of bioactive secondary metabolites (Iwamoto et al., 1990; Strohl, 2003; Piel, 2004). The majority of the members of this group share highly similar phenotypes and 16S rRNA sequences. However, reorganization of species within the $S$. griseus clade is a common occurrence. For example, based on DNA-DNA relatedness data, 'Streptomyces caviscabies', 'Streptomyces setonii' and 'Streptomyces argenteolus' have been transferred to S. griseus (Liu et al., 2005); 'S. griseus subsp. alpha' and 'S. griseus subsp. cretosus' have been transferred to Streptomyces microflavus (Lanoot et al., 2005b); and 'Streptomyces citreofluorescens', 'Streptomyces chrysomallus subsp. chrysomallus' and 'Streptomyces fluorescens' have been reassigned to Streptomyces anulatus (Lanoot et al., 2005b).

It is important to unravel the taxonomic relationships of reference streptomycetes at species level to guide the species discrimination and the discovery of potentially novel species for ecological reasons and industrial purposes. MLST (Multilocus Sequence Typing) (Maiden et al., 1998; Enright \& Spratt, 1999; Urwin \& Maiden, 2003) has been successfully applied to the unambiguous characterization of bacterial pathogens (Dingle et al., 2001; Adiri et al., 2003; Baldwin et al., 2005; Coffey et al., 2006), and to phylogenetic analysis of highly diverse bacterial groups, such as the genera Mycobacterium (Devulder et al., 2005), Pseudomonas (Hilario et al., 2004) and Haemophilus (Nørskov-Lauritsen et al., 2005), because of its lab-to-lab portability and reproducibility, and the demonstrated efficiency of inter- and intra-species resolution. In the present investigation, a streptomycete multilocus sequence analysis scheme was developed to clarify the bona fide taxonomic structure of the S. griseus $16 \mathrm{~S}$ rRNA gene clade. We selected six genes: $a t p D, \operatorname{gyr} B, \operatorname{rec} A, \operatorname{rpoB}, \operatorname{trp} B$ and $16 \mathrm{~S}$ rRNA, compared the phylogenetic trees derived from the sequence data, constructed a finer and more robust phylogeny, and set up a multilocus sequence database with open access on the internet. This study offers a primary multi-sequence-based framework for amending the systematics of Streptomyces, which facilitates our understanding of phylogeny and evolution of this genus.

\section{METHODS}

Bacterial strains and culture conditions. Of the 55 strains used in this study (listed in Table 1), 53 were from CGMCC/AS (China General Microbiological Culture Collection Centre, Institute of
Microbiology, Chinese Academy of Sciences, Beijing 100101, PR China); the other two strains were from BCCM/LMG (Collection of the Laboratorium voor Microbiologie en Microbiele Genetica, Rijksuniversiteit, Ledeganckstraat 35, B-9000, Gent, Belgium) and JCM (Japan Collection of Microorganisms, Institute of Physical and Chemical Research (RIKEN), Wako, Saitama 351-0198, Japan), respectively. The majority were type strains. Strains were cultured in yeast extract/malt extract agar (ISP 2; Shirling \& Gottlieb, 1966) at $28{ }^{\circ} \mathrm{C}$.

Selection of gene loci and design of primers. In addition to $16 \mathrm{~S}$ rRNA, five housekeeping genes, $a t p D, \operatorname{gyr} B, \operatorname{rec} A, \operatorname{rpoB}$ and $\operatorname{trp} B$, were chosen. Locations of all these genes on the Streptomyces coelicolor A3(2) genome map are shown in Fig. S1 (available with the online version of this paper). Primers for $a t p D, \operatorname{rec} A, \operatorname{rpo} B$ and $\operatorname{trp} B$ for amplification and sequencing were designed based on the corresponding sequences of S. coelicolor A3(2) (Bentley et al., 2002) and Streptomyces avermitilis (Ikeda et al., 2003), whose genomes are available in public databases. Software packages Primer premier 5.0 (Premier Biosoft International), Oligo 6.0 (Molecular Biology Insights) and SPCR 3.0 (http://moleco.sjtu.edu.cn/moleco/softwares. html) were used to design and evaluate the primers. For $g y r B$, amplification primers were derived from published primers PF-1 and PR-2, and sequencing primers from F-1 and R-4 (Hatano et al., 2003). The information for loci and primers used in this scheme are described in Table 2.

DNA extraction, amplification and sequencing. Genomic DNA was extracted from cultures grown on ISP 2 using the method of Moller et al. (1992). Each $50 \mu \mathrm{l}$ amplification reaction contained $1 \mu \mathrm{l}$ template DNA (50-200 ng), $5 \mu \mathrm{l} 10 \times$ PCR buffer, $1 \mu \mathrm{l}$ each PCR primer $(20 \mu \mathrm{M}), 1 \mu \mathrm{l} \mathrm{dNTP} \operatorname{mix}(10 \mathrm{mM}), 6 \mu \mathrm{l} \mathrm{MgCl}_{2}(25 \mathrm{mM})$, 2.5 U Taq DNA polymerase, $5 \mu \mathrm{L}$ DMSO and $29 \mu \mathrm{l}$ sterile MilliQ water. The reaction conditions were initial denaturation at $95{ }^{\circ} \mathrm{C}$ for $5 \mathrm{~min}$, followed by 30 cycles of denaturation at $95^{\circ} \mathrm{C}$ for $30 \mathrm{~s}$, annealing for $30 \mathrm{~s}$ at the primer-pair-specific annealing temperature (Table 2) and extension at $72{ }^{\circ} \mathrm{C}$ for $90 \mathrm{~s}$. A final extension was performed at $72{ }^{\circ} \mathrm{C}$ for $10 \mathrm{~min}$. Reaction products were electrophoresed on a $1 \%$ agarose gel and checked with ethidium bromide under UV light, and then purified and sequenced directly using a Taq DyeDeoxy Terminator Cycle Sequencing Kit and an ABI Prism 3730 automated DNA sequencer (Applied Biosystems). Both strands were sequenced as a cross-check by using forward and reverse sequencing primers.

Data analysis. Sequences of each locus were aligned using MEGA 3.1 software (Kumar et al., 2004), and trimmed manually at the same position before being used for further analysis and to set up a database on the internet (http://pubmlst.org/streptomyces). Statistics for each locus, such as the number and proportion of polymorphic sites, mean $\mathrm{G}+\mathrm{C}$ content, etc., were calculated using the START2 program (Jolley et al., 2001). Pairwise distances between sequences of each locus were calculated by using the Kimura two-parameter (K2P) model (Kimura, 1980). The $\mathrm{dN} / \mathrm{d} S$ ratios (the ratios of nonsynonymous to synonymous polymorphisms) were calculated by using the method of Nei \& Gojobori (1986) in START2.

To ensure the stability and reliability of phylogenetic relationships among strains used in this study, phylogenetic trees were constructed by using three different methods, neighbour-joining (NJ), maximumparsimony (MP) and maximum-likelihood (ML). The NJ and MP methods were from the MEGA 3.1 package with the option of complete deletion of gaps, and the ML method was from PHYLIP package version 3.66 (Felsenstein, 2006). The K2P model was chosen as a substitution model for all NJ tree constructions. Single-locus and sequence-concatenated trees, including concatenation of sequences of three and four random protein-coding loci and all five protein-coding 
Table 1. Strains used in this study, and GenBank accession numbers of alleles of loci

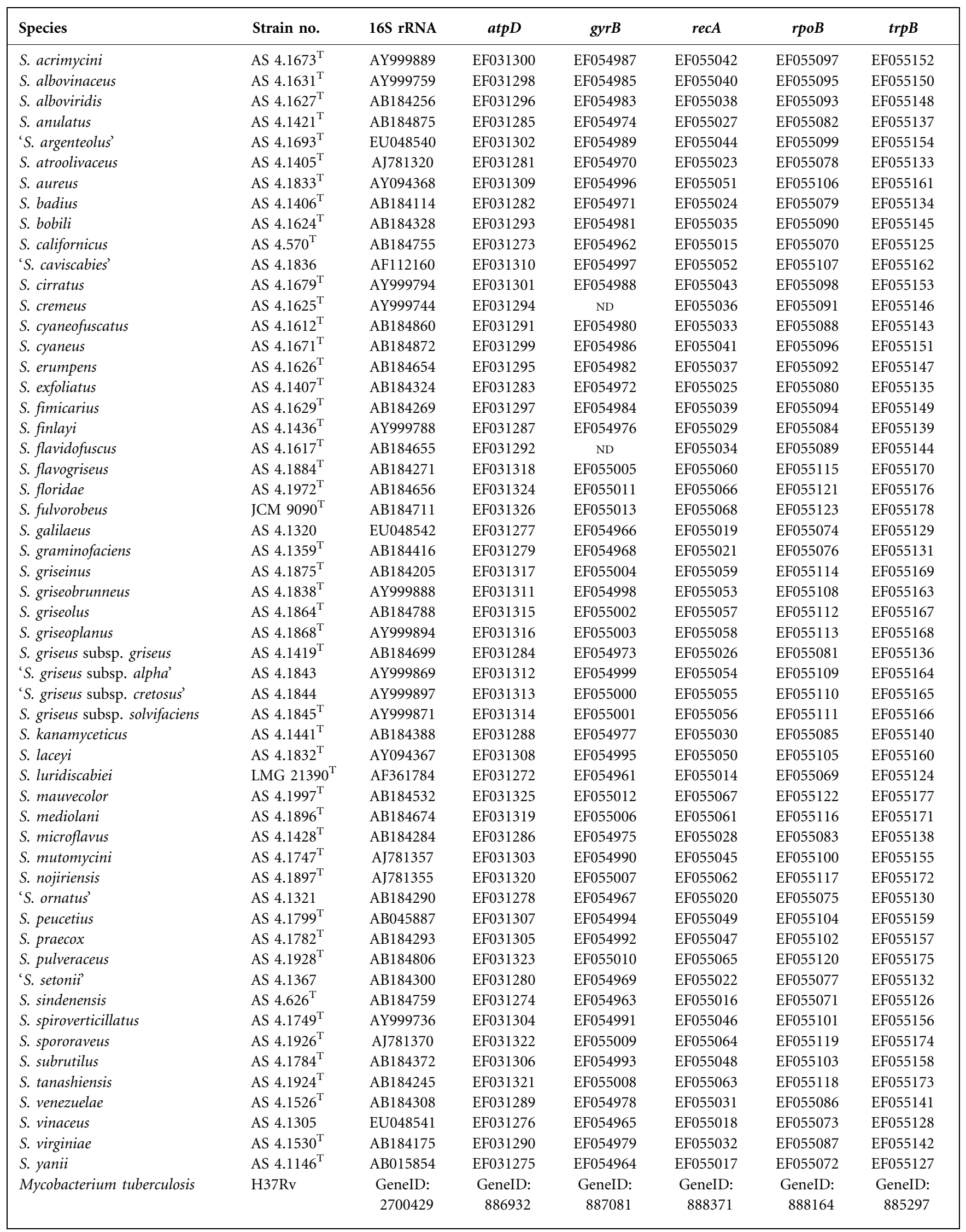

ND, Not determined. 
Table 2. Primers for amplification and sequencing

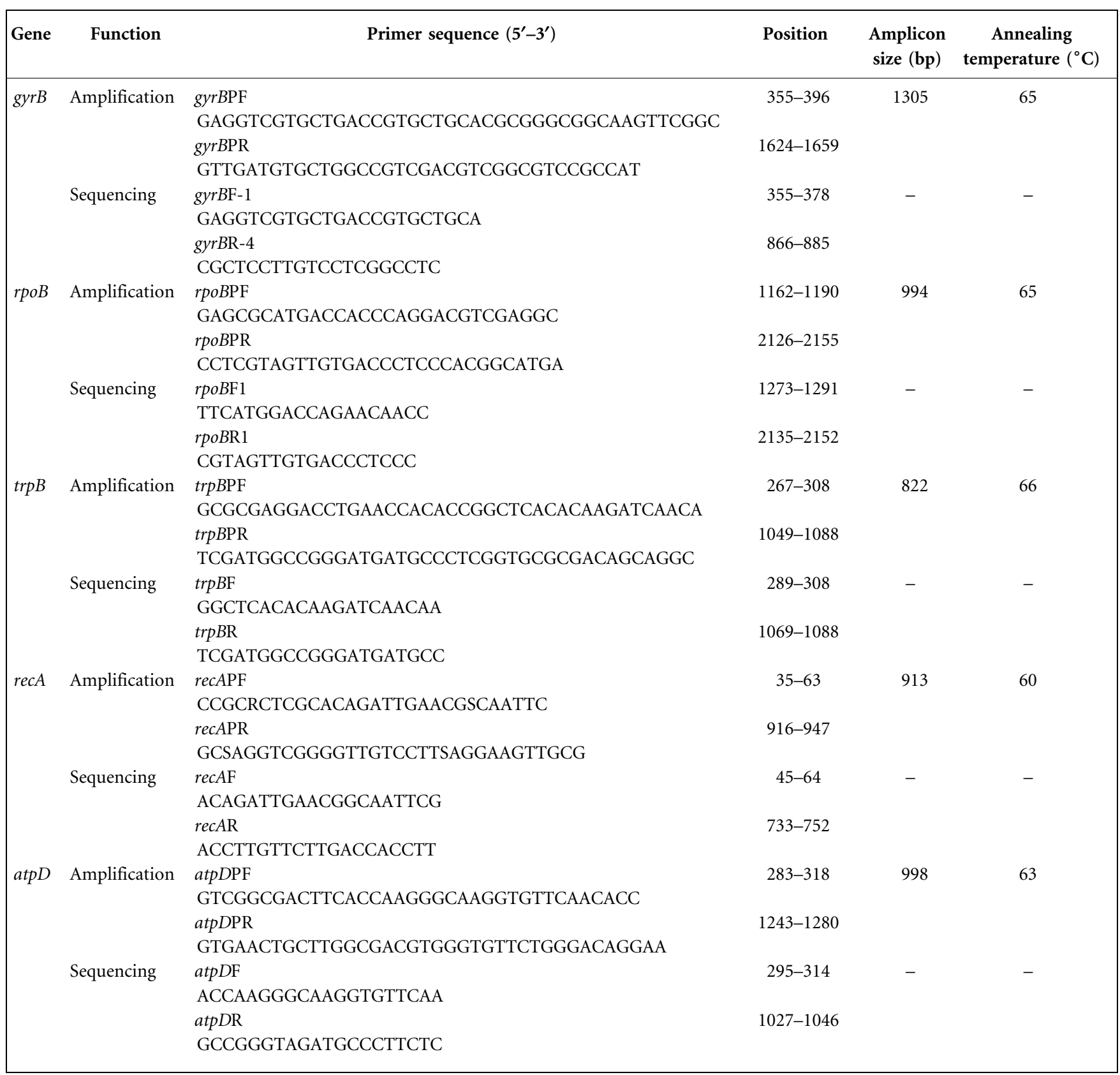

loci, were inferred including coding positions $(1 \mathrm{st}+2 \mathrm{nd}+3 \mathrm{rd}+$ noncoding). Concatenated sequences of all five protein-coding loci were joined head-to-tail in-frame. The bootstrap technique (Felsenstein, 1985) was employed to evaluate the tree topologies by resampling the sequence alignment 1000 times. Mycobacterium tuberculosis $\mathrm{H} 37 \mathrm{Rv}$ was used as the outgroup.

\section{RESULTS}

\section{Sequence attributes}

Amplification products from all 55 strains were obtained and each locus was subjected to sequencing. However, the
PCR products of gyrB from two strains (Streptomyces flavidofuscus and Streptomyces cremeus) could not be sequenced because the reverse primer for sequencing did not specifically match the template DNA of these strains. In the end, $496 \mathrm{bp}$ of $a t p D, 423 \mathrm{bp}$ of $g y r B$ (with gaps), $504 \mathrm{bp}$ of $r e c A, 540 \mathrm{bp}$ of $r p o B$ and $573 \mathrm{bp}$ of $\operatorname{trpB}$ (with gaps) were obtained. 16S rRNA gene sequences of the strains retrieved from the GenBank database and those determined in this study were aligned and trimmed to 459 bp (with gaps), corresponding to positions 59-485 of the 16S rRNA gene $(r r n B)$ sequence of $S$. coelicolor A3(2), containing the species-specific variable $\gamma$ region (158-203) (Anderson \& Wellington, 2001). GenBank accession 
numbers of the sequences used in this study are listed in Table 1.

The features of each locus are displayed in Table 3. The proportion of variable sites in the alleles varied from $20.4 \%$ (16S rRNA allele) to $48 \%$ ( $g y r B)$, in contrast with $15.5 \%$ variability in full-length $16 \mathrm{~S}$ rRNA sequences. The higher percentage of variable sites led to wider ranges of distance and higher mean $\mathrm{K} 2 \mathrm{P}$ distances, which made it possible to obtain finer relationships between close strains. Among the five protein-coding genes, gyrB had the largest mean K2P distance (0.140), significantly larger than that of the full-length $16 \mathrm{~S}$ rRNA sequence; atpD and recA shared a similar distance range and mean K2P distance, as did $r p o B$ and $\operatorname{trp} B$. With the exception of $16 \mathrm{~S}$ rRNA, the $\mathrm{G}+\mathrm{C}$ contents of the loci were close to the genomic $\mathrm{G}+\mathrm{C}$ content range of the genus Streptomyces, $67-78 \mathrm{~mol} \%$. The $\mathrm{dN} / \mathrm{d} S$ ratio is used to estimate the degree of selection operating on each locus. All of the $\mathrm{d} N / \mathrm{d} S$ values shown in Table 3 were much less than 1, indicating that most of the sequence variability identified is selectively neutral at protein level, validating their suitability for this multilocus sequence analysis scheme.

\section{$16 S$ rRNA gene trees}

The alignment and trimming of $16 \mathrm{~S}$ rRNA gene sequences produced $1406 \mathrm{nt}$ with gaps. Of these, $218(15.5 \%)$ sites were variable. The overall mean distance of 55 sequences was 0.020 . Comparing the trees constructed using the three treeing algorithms, we found poor congruence of the topology between each tree (Fig. 1). Bootstrap support for the trees was low: nodes with values less than $60 \%$ accounted for 21 out of 40 nodes $(52.5 \%)$ in the $\mathrm{NJ}$ tree, 41 out of 53 nodes $(77.4 \%)$ in the MP tree and $100 \%$ in the ML tree; in addition it cannot be neglected that 10 nodes in the MP tree have a bootstrap value of $0 \%$.

Looking at the NJ tree more closely, it is divided into two parts by the Streptomyces yanii and Streptomyces pulveraceus branch. All 29 strains constituting the compact and cohesive upper part (without S. yanii and S. pulveraceus) share high 16S rRNA gene sequence identities of
99.1-100\%, and contain four branches designated by four coloured clusters (Fig. 1); within each of these clusters the strains group together without divergence, sharing completely identical 16S rRNA gene sequences. S. griseus subsp. griseus forms cluster IV (red) with Streptomyces erumpens and 'Streptomyces ornatus', while 'S. griseus subsp. alpha' and 'S. griseus subsp. cretosus' belong to cluster III (green). It is interesting that $S$. griseus subsp. solvifaciens forms a distinct cluster with 'S. argenteolus', Streptomyces galilaeus and Streptomyces vinaceus at the bottom of the tree, and shares an equally low sequence identity of $95.4 \%$ with $S$. griseus subsp. griseus, S. griseus subsp. alpha and S. griseus subsp. cretosus. However, the levels of identity between $S$. griseus subsp. griseus and S. griseus subsp. alpha and $S$. griseus subsp. cretosus are $99.9 \%$ in both cases.

Strains in the lower part of the tree were generally well separated, except Streptomyces spororaveus and Streptomyces nojiriensis, and S. galilaeus, S. griseus subsp. solvifaciens and $S$. vinaceus. 16S rRNA gene sequence identities between strains in this part ranged from 87.1 to $100 \%$, with a mean distance of 0.033 . However, without $S$. flavidofuscus, the range of sequence identities narrowed to 95.0-100\%.

\section{Single and concatenated protein-coding-gene trees}

Phylogenetic trees for each protein-coding locus were constructed by using the three different methods (Supplementary Figs S2-S6, available with the online version of this paper). These trees, based on different loci, show general congruence. Clusters of strains indicated by different colours in the 16S rRNA gene tree (Fig. 1) are largely maintained in each single-gene tree, but with better discrimination. However, none of these genes alone contains enough phylogenetic information to reliably discriminate all species in the trees. The congruence among single-gene trees allows concatenation of multigene sequences for global analyses.

Sequences of three, four and five protein-coding genes were concatenated for phylogenetic analysis. It can be seen from

Table 3. Properties of loci

\begin{tabular}{|c|c|c|c|c|c|c|c|c|}
\hline Locus & $\begin{array}{l}\text { Allele length } \\
\text { (bp) }\end{array}$ & $\begin{array}{l}\text { No. of } \\
\text { alleles }\end{array}$ & $\begin{array}{c}\text { No. of } \\
\text { polymorphic sites }\end{array}$ & $\begin{array}{c}\text { Percentage of } \\
\text { polymorphic sites }\end{array}$ & $\begin{array}{c}\text { Mean G+C } \\
\text { content }(\mathrm{mol} \%)\end{array}$ & $\begin{array}{c}\text { Distance } \\
\text { range }^{\star}\end{array}$ & $\begin{array}{c}\text { Mean K2P } \\
\text { distance } \dagger\end{array}$ & $\mathrm{d} N / \mathrm{d} S$ \\
\hline $\operatorname{atpD}$ & 496 & 46 & 147 & 29.6 & 64.5 & $0-0.205$ & 0.081 & 0.1444 \\
\hline $\operatorname{rec} A$ & 504 & 44 & 168 & 33.3 & 68.9 & $0-0.204$ & 0.082 & 0.0677 \\
\hline$r p o B$ & 540 & 46 & 197 & 36.5 & 67.4 & $0-0.258$ & 0.090 & 0.2357 \\
\hline $\operatorname{trp} B$ & 573 & 51 & 232 & 40.5 & 72.6 & $0-0.304$ & 0.090 & 0.2647 \\
\hline 16S rRNA (full-length) & 1406 & 40 & 218 & 15.5 & 58.5 & $0-0.129$ & 0.017 & - \\
\hline
\end{tabular}

${ }^{*}$ Pairwise distance calculated by using the K2P substitution model.

$\dagger$ Distance calculated by using the K2P substitution model. 


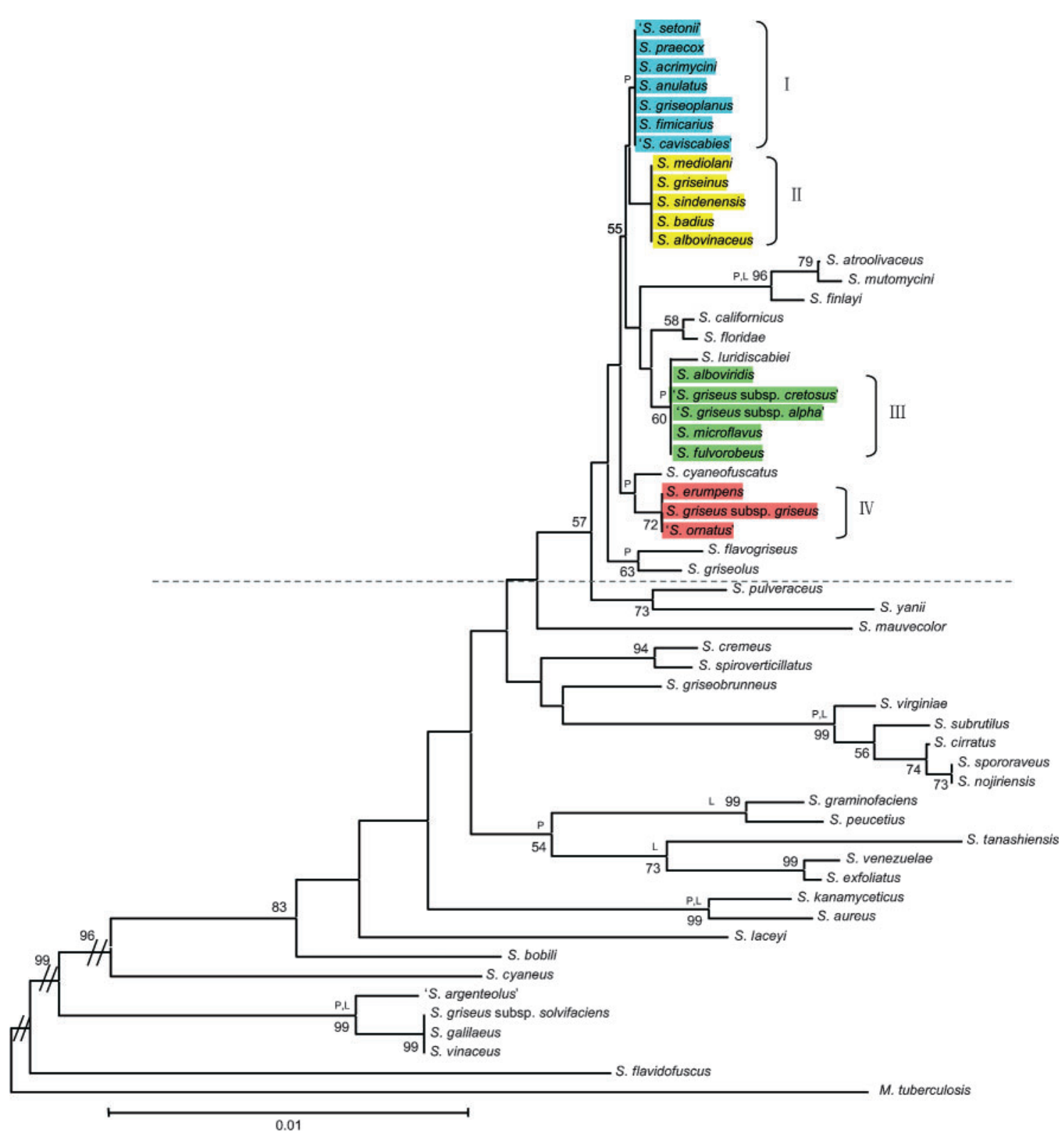

Fig. 1. Phylogenetic relationships among 55 Streptomyces strains based on 16S rRNA gene sequences. The tree was constructed using the NJ method. Mycobacterium tuberculosis H37Rv was used as the outgroup. Numbers at nodes represent levels (\%) of bootstrap support from 1000 resampled datasets. $L$ and $P$ indicate branches that were also recovered using $M L$ and MP methods, respectively. The bar indicates $1 \%$ estimated sequence divergence. Strains of clusters I, II, III and IV are highlighted with blue, yellow, green and red backgrounds, respectively.

the resultant trees (Supplementary Figs S7-S9, available with the online version of this paper) that, with the addition of each gene, the discriminatory power and the robustness of the trees increases slowly and regularly. Compared to the three- and four-gene trees, the five-gene tree holds bootstrap support that is slightly increased in the upper part, but greatly increased for the lower part, especially for the higher nodes, and gives enough resolution to separate closely related Streptomyces species.

\section{Six-gene trees}

The concatenated alignment of six loci contains $2900 \mathrm{nt}$ with a mean $\mathrm{G}+\mathrm{C}$ content of $67 \mathrm{~mol} \%$ and a mean pairwise distance of 0.079 . The sequence identities ranged from 88.3 to $100 \%$. Two-section division and a similar tendency of congruence and incongruence of each section were also observed for six-gene trees constructed by different methods (Fig. 2). The sequence identity range 


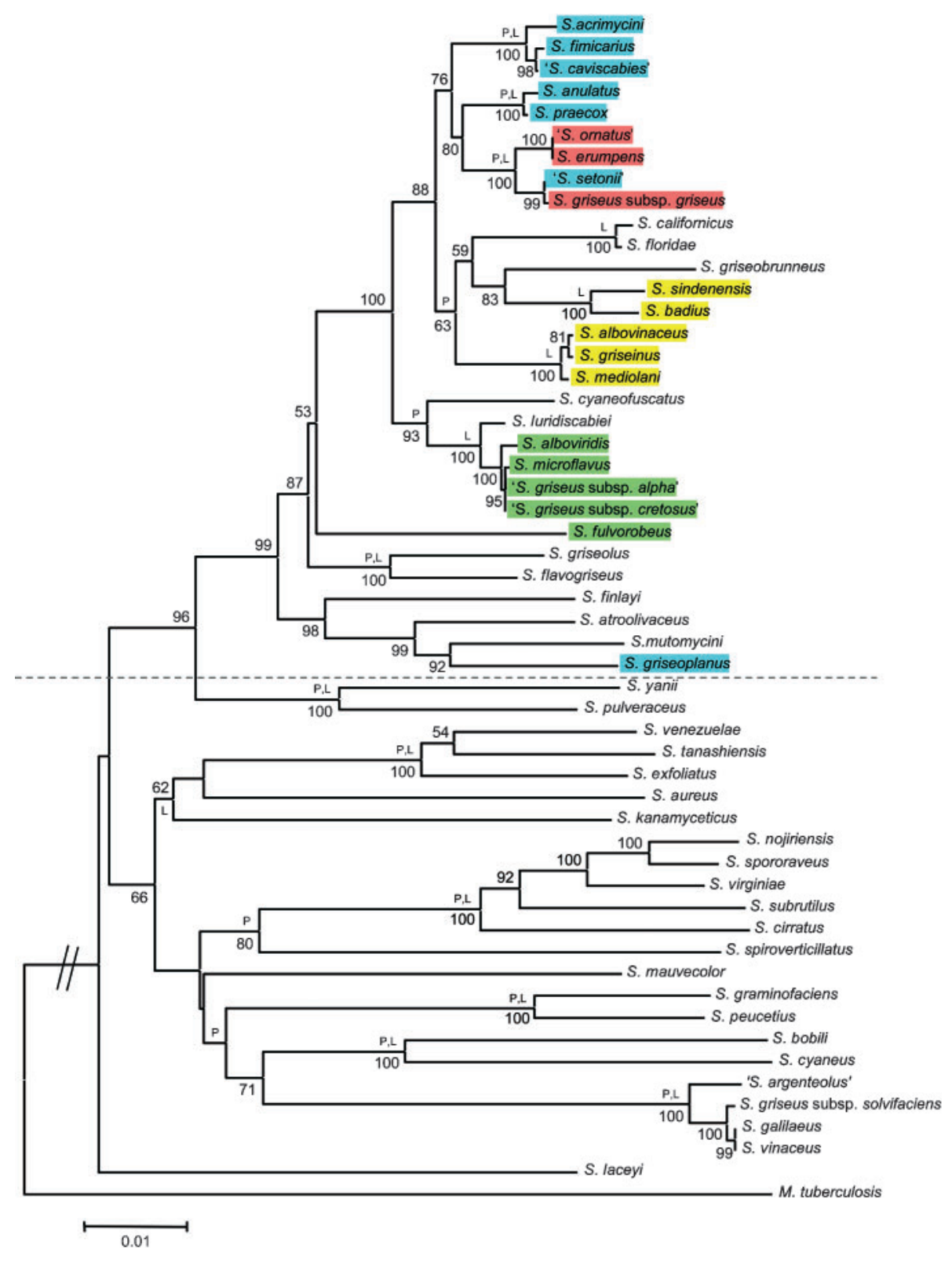

Fig. 2. Phylogenetic relationships among 53 Streptomyces strains based on six-gene concatenated sequences. The tree was constructed using the NJ method. Mycobacterium tuberculosis H37Rv was used as the outgroup. Numbers at nodes represent levels (\%) of bootstrap support from 1000 resampled datasets. $L$ and $P$ indicate branches that were also recovered using $M L$ and MP methods, respectively. The bar indicates $1 \%$ estimated sequence divergence. Strains of clusters I, II, III and IV are highlighted with blue, yellow, green and red backgrounds, respectively.

was $91.2-100 \%$ for the upper part and $88.3-99.7 \%$ for the lower part.

Strains of cluster I (blue), sharing 98.9-99.9\% identities (excluding Streptomyces griseoplanus) in six-gene concatenated sequences, were reliably differentiated as distinct entities. S. griseoplanus, placed in cluster I in the $16 \mathrm{~S}$ rRNA gene tree with zero distance, consistently falls into a distant branch in all multigene trees and was loosely related to Streptomyces atroolivaceus and Streptomyces mutomycini in the upper part neighbouring the boundary branch. Strains of cluster II (yellow), with identities of 97.2-99.9\%, were separated into two branches supported by high bootstrap values (100\%): Streptomyces sindenensis and Streptomyces badius were in a deep branch loosely related to Streptomyces griseobrunneus, while Streptomyces albovinaceus, Streptomyces griseinus and Streptomyces mediolani were in a higher branch as independent entities. All strains, with the exception of Streptomyces fulvorobeus in cluster III (green), were closely related within a branch, reflected by a 
sequence identity range of $99.8-100 \%$. 'S. griseus subsp. alpha', 'S. griseus subsp. cretosus' and S. microflavus consistently formed a closely related branch with zero distance, representing an S. microflavus complex. 'S. setonii' shifted from cluster I to cluster IV (red), which was separated into two stable branches with 99.3-100\% sequence identities and shared a higher node with members of cluster I.

In the lower part of the tree, bootstrap values were generally higher than those in five-gene trees, as demonstrated by $80 \%$ of nodes holding values over $60 \%$ in the NJ tree. The topological congruence between the three trees constructed by different methods is better than that between trees of five loci: high bootstrap values support the resemblance between deep branches of each tree, while the topology of some higher nodes remains unstable.

The six-gene tree proved to be the most robust and reliable phylogenetic tree that differentiated most strains in this study well, with the exceptions of $S$. griseus subsp. griseus and 'S. setonii', 'S. ornatus' and S. erumpens, S. microflavus, 'S. griseus subsp. alpha' and 'S. griseus subsp. cretosus', and S. galilaeus and S. vinaceus.

\section{DISCUSSION}

\section{Gene selection and primers}

Genes used in molecular systematics should be evaluated for their phylogenetic performance from historical (e.g. ease of amplification, previous analyses of related taxa) and analytical (e.g. copy number, rate of evolution) aspects (Hillis et al., 1996). The five protein-coding genes we selected are commonly used in the identification of bacteria, and some of them have been used individually for phylogenetic analyses of Streptomyces (Egan et al., 2001; Hatano et al., 2003; Kim et al., 2004). Each gene has only one copy on the S. coelicolor A3(2) genome, performs a different function in primary metabolism and is evolutionarily conserved. Primers designed for this multilocus sequence analysis scheme gave good results, but the sequencing primers of $g y r B$ derived from the literature (Hatano et al., 2003) performed inconsistently, although sequences were eventually obtained. New sequencing primers should be designed for future phylogenetic research using $g y r B$.

\section{Combinability of loci}

The suitability of the loci for this study was validated by their remote positions on the chromosome, low $\mathrm{dN} / \mathrm{d} S$ ratios and high content of informative sites (Table 3). The minimum distance between two loci ( $r r n E$ and recA) among the six distant genes is over $30 \mathrm{~kb}$ (Fig. S1), which means there is no genetic linkage between these loci theoretically. The low $d N / d S$ ratios (far below 1) indicated that the five housekeeping genes are not subjected to selection pressure for amino acid changes - they are selectively neutral. These properties guarantee the independence of each locus as they underwent evolution. Moreover, the variability of the loci, as demonstrated by the high proportion of polymorphic sites, and larger distance range and larger mean distance for each locus than for full-length $16 \mathrm{~S}$ rRNA gene sequences, implied that they would give a higher resolution for the phylogeny of the $S$. griseus clade than the $16 \mathrm{~S}$ rRNA gene. The widespread congruence between phylogenies recovered from individual genes indicated that the phylogenetic signals would not be counteracted when the loci are concatenated, thus making the combined analysis of different loci possible in this study.

\section{Phylogenetic resolution and reliability of single and combined datasets}

The 16S rRNA gene tree is unreliable based on the conflicting topologies and the low bootstrap support for the trees generated by different algorithms (Fig. 1), pointing to a significant probability of support for incorrect relationships for the strains included. The relationships of strains in the upper section are poorly resolved, especially strains in the coloured clusters. In contrast, strains in the lower section which share low sequence identities are largely well distinguished. So we can assume that the 16S rRNA gene is more appropriate for discrimination of (moderately) distantly related streptomycetes, but is not efficient for closely related strains such as those in clusters I-IV.

We found all five protein-coding loci to be informative, but not powerful or reproducible for all reference strains; our effort to construct well-resolved, deep phylogenies of Streptomyces was plagued by rate heterogeneity of different loci and weak phylogenetic signals in single genes. Therefore, we used multiple genes and, as expected, the effect of these problems was reduced considerably. Considering the potential systematic biases in different datasets, concatenation of the six genes would be optimal in resolving the relationships among all the strains. The strains that could not be discriminated in the six-gene tree belong to same species (Fig. 2). Lanoot et al. (2005b) transferred 'S. griseus subsp. alpha' and 'S. griseus subsp. cretosus' into S. microflavus because of their $100 \%$ DNADNA relatedness. 'S. setonii' has been transferred into $S$. griseus based on DNA-DNA relatedness (Liu et al., 2005) as well. In our study, all trees except the 16S rRNA gene tree reached a consensus that ' $S$. setonii' falls consistently into the closely related branch with $S$. griseus subsp. griseus, which is in agreement with the result of DNA-DNA relatedness. 'S. ornatus' and S. erumpens have identical sixgene concatenated sequences, with which $S$. griseus subsp. griseus shares $99.3 \%$ sequence identity. DNA-DNA relatedness data from previous studies (Okanishi, 1972; Liu et al., 2005) support 'S. ornatus' belonging to the same genomic species as the type strain of $S$. griseus. Based on 
results of present and previous studies, we propose that ' $S$. ornatus', S. erumpens, 'S. setonii', and S. griseus subsp. griseus should be considered as members of the same genomic species, S. griseus, which however, should not encompass ' $S$. caviscabies' based on their well-separated locations in the multigene trees. The two remaining strains, S. galilaeus and S. vinaceus, which share identical sequences of all six genes, do not merit separate species status, because their 16S rRNA gene sequences (EU048542 and EU048541) determined in this study are evidently different from those ( $\mathrm{AB} 045878$ and $\mathrm{AB} 184394)$ of the respective type strains (with distances of 0.042-0.044), and they should be assigned to a single species with a different name.

In light of the clear differentiation of all strains at species level by the six-gene tree and the accordance between data of this study and DNA-DNA relatedness studies, our multilocus sequence analysis scheme based on a combined analysis of the six loci gives credible and appropriate phylogenetic resolution at species level for the S. griseus $16 \mathrm{~S}$ rRNA gene clade.

\section{Comparison between 16S rRNA gene and concatenated trees}

The upper parts of NJ trees include almost the same closely related strains except $S$. griseobrunneus, which failed to appear in the same position as in the 16S rRNA gene tree and moved to the upper part in the concatenated trees, with S. badius and S. sindenensis of cluster II as its consistent neighbours. Another strain with noticeably different positions within the upper part of the trees is $S$. griseoplanus (cluster I), as mentioned above. To check the incongruence observed for these two strains between the $16 \mathrm{~S}$ rRNA gene and concatenated trees, we sequenced their $16 \mathrm{~S}$ rRNA gene again, but obtained identical sequences as those retrieved from GenBank, which we had used. This result reveals the misleading probability of using the $16 \mathrm{~S}$ rRNA gene solely for phylogenetic relationships.

Three species with abnormal taxonomic positions were observed in both the 16S rRNA gene and concatenated trees. One is ' $S$. argenteolus', which always clusters with $S$. griseus subsp. solvifaciens, S. galilaeus and S. vinaceus in the lower part of all trees, supported by high bootstrap values. Since it is separated from S. griseus subsp. griseus in the $16 \mathrm{~S}$ rRNA gene tree with a phylogenetic distance of 0.046 , and in the six-gene tree with a significant distance of 0.103 , we suggest that ' $S$. argenteolus' AS $4.1693^{\mathrm{T}}$ merits species status distinct from $S$. griseus, rather than being a member of the latter species as proposed by Liu et al. (2005). The 16S rRNA gene sequence (EU048540) obtained for this strain in our study is markedly divergent (with a distance of 0.051) from those (AB045872 and $\mathrm{AB} 184187)$ obtained previously for 'S. argenteolus' JCM $4623^{\mathrm{T}}$ (=NBRC $\left.12841^{\mathrm{T}}\right)$. The second is S. griseus subsp. solvifaciens that was located unusually far from $S$. griseus subsp. griseus in all trees. Combined with its genotypical heterogeneity with other members of S. griseus as reported by Lanoot et al. (2005b), we propose that S. griseus subsp. solvifaciens should be removed from S. griseus. Additional analyses with more Streptomyces species are needed to clarify its taxonomic status. The third is S. flavidofuscus that was consistently located at the periphery of the other streptomycetes selected in this study. Further examination demonstrated that this type strain had sequences very different from that of other strains at all loci, but shared high 16S rRNA gene sequence similarities with strains of Nocardiopsis [e.g. 99.5\% identity with Nocardiopsis synnemataformans DSM $44143^{\mathrm{T}}$ (Y13593)] as determined by a BLAST search against the GenBank database. Therefore, we propose that S. flavidofuscus should be transferred to the genus Nocardiopsis. Therefore, S. griseobrunneus, S. griseoplanus, 'S. argenteolus', $S$. griseus subsp. solvifaciens and S. flavidofuscus, whose taxonomic positions have significantly changed, may be worth looking at again for potentially useful metabolites.

Several points can be obtained from comparison of the concatenated six-gene and 16S rRNA gene trees. First, the phylogenetic relationships among most strains in this study are generally congruent between the two trees. Second, the six-gene tree shows a much higher power of discrimination in that most species are clearly discriminated from each other, especially the closely related species in clusters I-IV, and the overall mean distance of the six-gene tree (0.079) is significantly greater than that of the $16 \mathrm{~S}$ rRNA gene tree (0.020). Third, the topological structure of the six-gene tree, which is supported by noticeably higher bootstrap values, is much more stable than that of the 16S rRNA gene tree. These points emphasize the fact that the six-gene tree is obviously superior to the $16 \mathrm{~S}$ rRNA gene tree in both resolution power and topological stability. Moreover, the concatenation of a sufficient number of genes overwhelms possible conflicting phylogenetic signals in different genes.

In conclusion, we have developed a pilot multilocus sequence analysis scheme for Streptomyces, and have shown its promising potential for refining the phylogeny of this genus. Our scheme, based on combined analysis of sequence variations at six different loci, can discriminate and define phylogenetic relationships among diverse and closely related species of the $S$. griseus $16 \mathrm{~S}$ rRNA gene clade. We believe that this multilocus sequence analysis scheme can be applied further to more taxonomically diverse actinomycete taxa where identification and discrimination are valuable tools in the discovery of novel and commercially important metabolites.

\section{ACKNOWLEDGEMENTS}

We are grateful to Dr Keith Jolley (University of Oxford) for his excellent technical assistance in the construction of the multilocus sequence internet database and to Professor John Mekalanos (Harvard Medical School) for his help in editing the manuscript. We also thank CGMCC/AS, BCCM/LMG and JCM for providing reference strains. This work was funded by the Natural Science Foundation of China (NSFC, No. 30670002) and by the Knowledge Innovation Project of Chinese Academy of Sciences (No. KSCX2-YW-Z-042). 


\section{REFERENCES}

Adiri, R. S., Gophna, U. \& Ron, E. Z. (2003). Multilocus sequence typing (MLST) of Escherichia coli O78 strains. FEMS Microbiol Lett 222, 199-203.

Anderson, A. S. \& Wellington, E. M. (2001). The taxonomy of Streptomyces and related genera. Int J Syst Evol Microbiol 51, 797-814

Baldwin, A., Mahenthiralingam, E., Thickett, K. M., Honeybourne, D., Maiden, M. C., Govan, J. R., Speert, D. P., Lipuma, J. J., Vandamme, P. \& Dowson, C. G. (2005). Multilocus sequence typing scheme that provides both species and strain differentiation for the Burkholderia cepacia complex. J Clin Microbiol 43, 4665-4673.

Bentley, S. D., Chater, K. F., Cerdeno-Tarraga, A. M., Challis, G. L., Thomson, N. R., James, K. D., Harris, D. E., Quail, M. A., Kieser, H. \& other authors (2002). Complete genome sequence of the model actinomycete Streptomyces coelicolor A3(2). Nature 417, 141-147.

Berdy, J. (2005). Bioactive microbial metabolites. J Antibiot 58, 1-26.

Clardy, J., Fischbach, M. A. \& Walsh, C. T. (2006). New antibiotics from bacterial natural products. Nat Biotechnol 24, 1541-1550.

Coffey, T. J., Pullinger, G. D., Urwin, R., Jolley, K. A., Wilson, S. M., Maiden, M. C. \& Leigh, J. A. (2006). First insights into the evolution of Streptococcus uberis: a multilocus sequence typing scheme that enables investigation of its population biology. Appl Environ Microbiol 72, $1420-1428$

Devulder, G., Pérouse de Montclos, M. \& Flandrois, J. P. (2005). A multigene approach to phylogenetic analysis using the genus Mycobacterium as a model. Int J Syst Evol Microbiol 55, 293-302.

Dingle, K. E., Colles, F. M., Wareing, D. R., Ure, R., Fox, A. J., Bolton, F. E., Bootsma, H. J., Willems, R. J., Urwin, R. \& Maiden, M. C. (2001). Multilocus sequence typing system for Campylobacter jejuni. J Clin Microbiol 39, 14-23.

Egan, S., Wiener, P., Kallifidas, D. \& Wellington, E. M. (2001) Phylogeny of Streptomyces species and evidence for horizontal transfer of entire and partial antibiotic gene clusters. Antonie van Leeuwenhoek 79, 127-133.

Enright, M. C. \& Spratt, B. G. (1999). Multilocus sequence typing. Trends Microbiol 7, 482-487.

Felsenstein, J. (1985). Confidence limits on phylogenies: an approach using the bootstrap. Evolution 39, 783-791.

Felsenstein, J. (2006). PHYLIP (phylogeny inference package). Version 3.66. Department of Genome Sciences, University of Washington, Seattle, USA.

Grund, E., Knorr, C. \& Eichenlaub, R. (1990). Catabolism of benzoate and monohydroxylated benzoates by Amycolatopsis and Streptomyces spp. Appl Environ Microbiol 56, 1459-1464.

Hatano, K., Nishii, T. \& Kasai, H. (2003). Taxonomic re-evaluation of whorl-forming Streptomyces (formerly Streptoverticillium) species by using phenotypes, DNA-DNA hybridization and sequences of gyrB, and proposal of Streptomyces luteireticuli (ex Katoh and Arai 1957) corrig., sp. nov., nom. rev. Int J Syst Evol Microbiol 53, 1519-1529.

Hilario, E., Buckley, T. R. \& Young, J. M. (2004). Improved resolution on the phylogenetic relationships among Pseudomonas by the combined analysis of atpD, carA, recA and $16 \mathrm{~S}$ rDNA. Antonie Van Leeuwenhoek 86, 51-64.

Hillis, D. M., Moritz, C. \& Mable, B. K. (1996). Molecular Systematics. Sunderland, MA: Sinauer Associates.

Ikeda, H., Ishikawa, J., Hanamoto, A., Shinose, M., Kikuchi, H., Shiba, T., Sakaki, Y., Hattori, M. \& Omura, S. (2003). Complete genome sequence and comparative analysis of the industrial microorganism Streptomyces avermitilis. Nat Biotechnol 21, 526-531.
Ishiyama, D., Vujaklija, D. \& Davies, J. (2004). Novel pathway of salicylate degradation by Streptomyces sp. strain WA46. Appl Environ Microbiol 70, 1297-1306.

Iwamoto, T., Tsujii, E., Ezaki, M., Fujie, A., Hashimoto, S., Okuhara, M., Kohsaka, M., Imanaka, H., Kawabata, K. \& other authors (1990). FR109615, a new antifungal antibiotic from Streptomyces setonii. Taxonomy, fermentation, isolation, physico-chemical properties and biological activity. J Antibiot 43, 1-7.

Jolley, K. A., Feil, E. J., Chan, M. S. \& Maiden, M. C. (2001). Sequence type analysis and recombinational tests (START). Bioinformatics 17, $1230-1231$.

Kim, B.-J., Kim, C.-J., Chun, J., Koh, Y.-H., Lee, S.-H., Hyun, J.-W., Cha, C.-Y. \& Kook, Y.-H. (2004). Phylogenetic analysis of the genera Streptomyces and Kitasatospora based on partial RNA polymerase $\beta$ subunit gene (rpoB) sequences. Int J Syst Evol Microbiol 54, 593-598.

Kimura, M. (1980). A simple method for estimating evolutionary rates of base substitutions through comparative studies of nucleotide sequences. J Mol Evol 16, 111-120.

Kumar, S., Tamura, K. \& Nei, M. (2004). MEGA3: integrated software for Molecular Evolutionary Genetics Analysis and sequence alignment. Brief Bioinform 5, 150-163.

Lanoot, B., Vancanneyt, M., Dawyndt, P., Cnockaert, M., Zhang, J., Huang, Y., Liu, Z. \& Swings, J. (2004). BOX-PCR fingerprinting as a powerful tool to reveal synonymous names in the genus Streptomyces. Emended descriptions are proposed for the species Streptomyces cinereorectus, S. fradiae, S. tricolor, S. colombiensis, S. filamentosus, S. vinaceus and S. phaeopurpureus. Syst Appl Microbiol 27, 84-92.

Lanoot, B., Vancanneyt, M., Hoste, B., Vandemeulebroecke, K., Cnockaert, M. C., Dawyndt, P., Liu, Z., Huang, Y. \& Swings, J. (2005a). Grouping of streptomycetes using 16S-ITS RFLP fingerprinting. Res Microbiol 156, 755-762.

Lanoot, B., Vancanneyt, M., Van Schoor, A., Liu, Z. \& Swings, J. (2005b). Reclassification of Streptomyces nigrifaciens as a later synonym of Streptomyces flavovirens; Streptomyces citreofluorescens, Streptomyces chrysomallus subsp. chrysomallus and Streptomyces fluorescens as later synonyms of Streptomyces anulatus; Streptomyces chibaensis as a later synonym of Streptomyces corchorusii; Streptomyces flaviscleroticus as a later synonym of Streptomyces minutiscleroticus; and Streptomyces lipmanii, Streptomyces griseus subsp. alpha, Streptomyces griseus subsp. cretosus and Streptomyces willmorei as later synonyms of Streptomyces microflavus. Int J Syst Evol Microbiol 55, 729-731.

Liu, Z., Shi, Y., Zhang, Y., Zhou, Z., Lu, Z., Li, W., Huang, Y., Rodriguez, C. \& Goodfellow, M. (2005). Classification of Streptomyces griseus (Krainsky 1914) Waksman and Henrici 1948 and related species and the transfer of 'Microstreptospora cinerea' to the genus Streptomyces as Streptomyces yanii sp. nov. Int J Syst Evol Microbiol 55, 1605-1610.

Maiden, M. C., Bygraves, J. A., Feil, E., Morelli, G., Russell, J. E., Urwin, R., Zhang, Q., Zhou, J., Zurth, K. \& other authors (1998). Multilocus sequence typing: a portable approach to the identification of clones within populations of pathogenic microorganisms. Proc Natl Acad Sci U S A 95, 3140-3145.

Moller, E. M., Bahnweg, G., Sandermann, H. \& Geiger, H. H. (1992). A simple and efficient protocol for isolation of high molecular weight DNA from filamentous fungi, fruit bodies, and infected plant tissues. Nucleic Acids Res 20, 6115-6116.

Nei, M. \& Gojobori, T. (1986). Simple methods for estimating the numbers of synonymous and nonsynonymous nucleotide substitutions. Mol Biol Evol 3, 418-426.

Nørskov-Lauritsen, N., Bruun, B. \& Kilian, M. (2005). Multilocus sequence phylogenetic study of the genus Haemophilus with description of Haemophilus pittmaniae sp. nov. Int J Syst Evol Microbiol 55, 449-456. 
Okanishi, M. (1972). An evaluation of taxonomic criteria in streptomycetes on the basis of deoxyribonucleic acid homology. J Gen Microbiol 72, 49-58.

Phelan, M. B., Crawford, D. L. \& Pometto, A. L., III (1979). Isolation of lignocellulose-decomposing actinomycetes and degradation of specifically 14C-labeled lignocelluloses by six selected Streptomyces strains. Can J Microbiol 25, 1270-1276.

Piel, J. (2004). Metabolites from symbiotic bacteria. Nat Prod Rep 21, 519-538.

Shirling, E. B. \& Gottlieb, D. (1966). Methods for characterization of Streptomyces species. Int J Syst Bacteriol 16, 313-340.
Song, J., Lee, S. C., Kang, J. W., Baek, H. J. \& Suh, J. W. (2004). Phylogenetic analysis of Streptomyces spp. isolated from potato scab lesions in Korea on the basis of 16S rRNA gene and 16S-23S rDNA internally transcribed spacer sequences. Int J Syst Evol Microbiol 54, 203-209.

Strohl, W. R. (2003). Antimicrobials. In Microbial Diversity and Bioprospecting, pp. 336-355. Edited by A. T. Bull. ASM Press.

Urwin, R. \& Maiden, M. C. (2003). Multi-locus sequence typing: a tool for global epidemiology. Trends Microbiol 11, 479-487.

Watve, M. G., Tickoo, R., Jog, M. M. \& Bhole, B. D. (2001). How many antibiotics are produced by the genus Streptomyces? Arch Microbiol 176, 386-390. 